\title{
Hot Deformation Behavior and Microstructural Characteristics of Ti-46Al-8Nb Alloy
}

\author{
Tian-Rui $\mathrm{Li}^{1} \cdot$ Guo-Huai Liu ${ }^{1} \cdot$ Mang $\mathrm{Xu}^{1} \cdot$ Tian-Liang $\mathrm{Fu}^{1} \cdot$ Yong Tian ${ }^{1} \cdot \mathrm{Ra}-J a$ Devesh Kumar Misra ${ }^{2} \cdot$ \\ Zhao-Dong Wang ${ }^{1}$
}

Received: 28 November 2017/Revised: 20 January 2018/Published online: 21 May 2018

(C) The Chinese Society for Metals and Springer-Verlag GmbH Germany, part of Springer Nature 2018

\begin{abstract}
Hot deformation behavior, microstructural evolution and flow softening mechanism were investigated in Ti-46Al-8Nb alloy via isothermal compression approach. The true stress-strain curves exhibited typical work hardening and flow softening, in which the dependence of the peak stress on temperature and strain rate was obtained by hyperbolic sine equation with Zener-Hollomon $(Z)$ parameter, and the activation energy was calculated to be $446.9 \mathrm{~kJ} / \mathrm{mol}$. The microstructural analysis shows that the alternate dark and light deformed ribbons of Al-rich and Nb-rich regions appeared and were associated with local flow involving solute segregation. The Al segregation promoted flow softening mainly arising from the recrystallization of $\gamma$ phase with low stacking fault energy. The coarse recrystallized $\gamma$ and several massive $\gamma$ phase were observed at grain boundaries. While in the case of $\mathrm{Nb}$ segregation, $\beta / \mathrm{B} 2$ phase harmonized bending of lamellae, combined with the growth of recrystallized $\gamma$ grains and $\alpha+\beta+\gamma \rightarrow \alpha+\gamma$ transition under conditions of temperature and stress, leading to the breakdown of $\alpha_{2} / \gamma$ lamellar colony. During the hot compression process, gliding and dissociation of dislocations occurred in $\gamma$ phase that acted as the main softening mechanism, leading to extensive $\gamma$ twins and cross twins in $\alpha / \gamma$ lamellae and at grain boundaries. In general, homogeneous microstructure during the hot deformation process can be obtained in $\mathrm{TiAl}$ alloy with high $\mathrm{Nb}$ addition and low $\mathrm{Al}$ segregation. The deformation substructures intrinsically promote the formability of $\mathrm{Ti}-46 \mathrm{Al}-8 \mathrm{Nb}$ alloy.
\end{abstract}

Keywords Titanium aluminides - Deformation behavior - Activation energy · Dynamic recrystallization · Local flow softening

\section{Introduction}

TiAl-based alloys are promising for high-temperature structural applications because of their excellent low density, high-temperature strength, high specific modulus and creep resistance [1-4]. Recently, high-Nb TiAl alloys (Ti45-46Al-5-9Nb-C, B, Y) were studied as high-

Available online at http://link.springer.com/journal/40195

Guo-Huai Liu

liugh@ral.neu.edu.cn

1 State Key Laboratory of Rolling and Automation, Northeastern University, Shenyang 110819, China

2 Laboratory for Excellence in Advanced Steel Research, Department of Metallurgical, Materials and Biomedical Engineering, University of Texas at El Paso, El Paso, TX 79968-0521, USA temperature TiAl alloys, for turbines of aircraft engines and gas-burning power-generation plants [5-7]. Unfortunately, the widespread application of TiAl-Nb alloys is limited because of low-temperature brittleness and poor workability [8-10]. This requires tuning of thermo-mechanical treatment to obtain fine microstructure and improved ductility $[11,12]$.

In the case of TiAl-Nb alloy, the high $\mathrm{Nb}$ addition may significantly change the TiAl phase diagram greatly, leading to multiphase structure and complex microstructure because of solute segregation, which can easily produce cracks, localized flow stress and microstructural inhomogeneity during the hot deformation process $[13,14]$. The improved deformability depends on optimizing the deformation temperature, strain rate and strain-stress conditions.

Additionally, the high- $\mathrm{Nb} \mathrm{TiAl}$ alloys studied previously $[15,16]$ had inhomogeneous microstructure and severe solute segregation ( $S$-, $\beta$ - and $\alpha$-segregation), which may 
aggravate local flow during deformation, retained-bulk $\alpha_{2}$ / $\gamma$ lamellae and partially recrystallized during the hot deformation process. The solute $\mathrm{Al}$ and $\mathrm{Nb}$ segregation has significant effect on stacking fault energy of TiAl alloy, which may lead to localized flow and inhomogeneous microstructure $[17,18]$. Limited attention has been given to the deformation substructure of high- $\mathrm{Nb} \mathrm{TiAl}$ alloy, which may promote distinct dynamic recrystallization (DRX). Therefore, it is significant to investigate the hot deformation and the origin of dislocations and twinning of $\mathrm{Ti}-$ $46 \mathrm{Al}-8 \mathrm{Nb}$ alloy so that the DRX mechanism in TiAl as well as the deformation of lamellae can be clearly explained. On the other hand, the bcc B2 phase from the $\beta$ stabilizer is added to improve hot deformability, because it is softer than $\alpha$ and $\gamma$ phases at elevated temperature. This has been studied for the deformation process in $\mathrm{Ti}-47 \mathrm{Al}-$ 2Cr-0.2Mo, Ti-47Al-2Cr-1Nb and $\mathrm{Ti}-44 \mathrm{Al}-4 \mathrm{Nb}-1 \mathrm{Mo}-$ (B, Si), etc. [19-22]. But the contribution of B2 phase is not deeply understood depending on the origin, morphology and distribution in TiAl-Nb alloys.

In this study, the hot deformation behavior and microstructure of $\mathrm{Ti}-46 \mathrm{Al}-8 \mathrm{Nb}$ alloy were studied by isothermal compression process. First, the stress exponent $(n)$ and hot deformation activation energy $(Q)$ were obtained by inducing Zener-Hollomon $(Z)$ parameter to understand the hot deformation of $\mathrm{Ti}-46 \mathrm{Al}-8 \mathrm{Nb}$ alloy, and then the microstructural evolution and flow softening mechanism with various $Z$ values were analyzed. Finally, the particular interest was on the effect of the solute segregation, multiphase structure, and deformation substructure on the local flow behavior to control the microstructure and deformability of high-Nb TiAl alloys.

\section{Experimental Procedure}

The intermetallic Ti-46Al-8Nb (at.\%) alloy with an actual composition of $\mathrm{Ti}-46.3 \mathrm{Al}-7.6 \mathrm{Nb}$ (at.\%) measuring approximately $\Phi 110 \mathrm{~mm} \times 400 \mathrm{~mm}$ was supplied in the form of cast cylindrical ingot, which was fabricated by the induction skull melting (ISM) under argon atmosphere. Cylindrical compressive samples with a diameter of $8 \mathrm{~mm}$ and a height of $15 \mathrm{~mm}$ were cut with an electric discharge machining perpendicular to the radial direction of the ingot in the center zone. Simulating isothermal compression tests were conducted on an MMS-300 thermo-simulator machine in an argon atmosphere in the temperature range of $1100-1250{ }^{\circ} \mathrm{C}$ and strain rates of $0.001-1 \mathrm{~s}^{-1}$. The samples were heated at a rate of $5{ }^{\circ} \mathrm{C} / \mathrm{s}$ and homogenized for $5 \mathrm{~min}$ at these test temperatures. All the samples were deformed to 0.6 true strain during compression and then water quenched to room temperature to study the microstructural evolution during deformation. To reduce the friction, graphite papers were used between the samples and the machine grips. The deformed specimens were sectioned parallel to the compression axis for microstructural analysis.

The microstructure was characterized by scanning electron microscopy (SEM) in backscattered electron (BSE) mode, transmission electron microscopy (TEM) and electron backscattered diffraction (EBSD) techniques. The specimens for SEM observations were polished using standard metallographic procedure, while specimens for TEM were prepared by ion beam thinning. Electro-polishing was carried out in a solution consisting of 5 vol\% perchloric acid +35 vol\% butanol +60 vol $\%$ methanol at $-20{ }^{\circ} \mathrm{C}$ and $25 \mathrm{~V}$ to prepare EBSD samples. The EBSD data at intervals of $0.2 \mu \mathrm{m}$ were collected and analyzed by the OIM software.

\section{Results and Discussion}

\subsection{Microstructure}

Figure 1 shows the microstructure of as-cast $\mathrm{Ti}-46 \mathrm{Al}-8 \mathrm{Nb}$ alloy. The multiphase microstructure and solute segregation can be observed by SEM and TEMs. The lamellar colonies with alternating $\gamma$ and $\alpha_{2}$ phases were obtained from the $\alpha \rightarrow \gamma+\alpha_{2}$ transition with $0.2-0.8 \mu \mathrm{m}$ spacing, as shown in Fig. 1b. Additionally, $\gamma$ phases at the grain boundaries and $\mathrm{B} 2$ phase with $\mathrm{Nb}$ enrichment in the core of the lamellar colonies were observed by TEM, as shown in Fig. 1c, d. The net-like Al segregation with black contrast and $\mathrm{Nb}$ segregation with white contrast exist in $\mathrm{Ti}-46 \mathrm{Al}-$ $8 \mathrm{Nb}$ alloy, which mainly resulted from the peritectic reaction and low diffusivity of $\mathrm{Nb}$ [23]. The multiphase structure and high solute segregation in $\mathrm{Ti}-46 \mathrm{Al}-8 \mathrm{Nb}$ alloy may give rise to local flow and complex recrystallization process during hot deformation.

\subsection{Flow Stress-Strain}

The hot deformation process of TiAl alloys is sensitive to temperature, strain rate and extent of deformation, during which dislocations slide, climb and twins are nucleated, controlled by the thermal activation process. Then ZenerHollomon $(Z)$ parameter and thermal activation coefficients are introduced to establish the dependency of flow behavior on hot-deformed conditions in $\mathrm{Ti}-46 \mathrm{Al}-8 \mathrm{Nb}$ alloy.

The true stress-strain curves obtained from isothermal compression tests of the as-cast $\mathrm{Ti}-46 \mathrm{Al}-8 \mathrm{Nb}$ alloys are shown in Fig. 2. The flow stress rises rapidly with strain during the early stage of dislocation multiplication and exhibits a peak at a strain. The curve is followed by decrease of flow stress to a steady state with increasing 

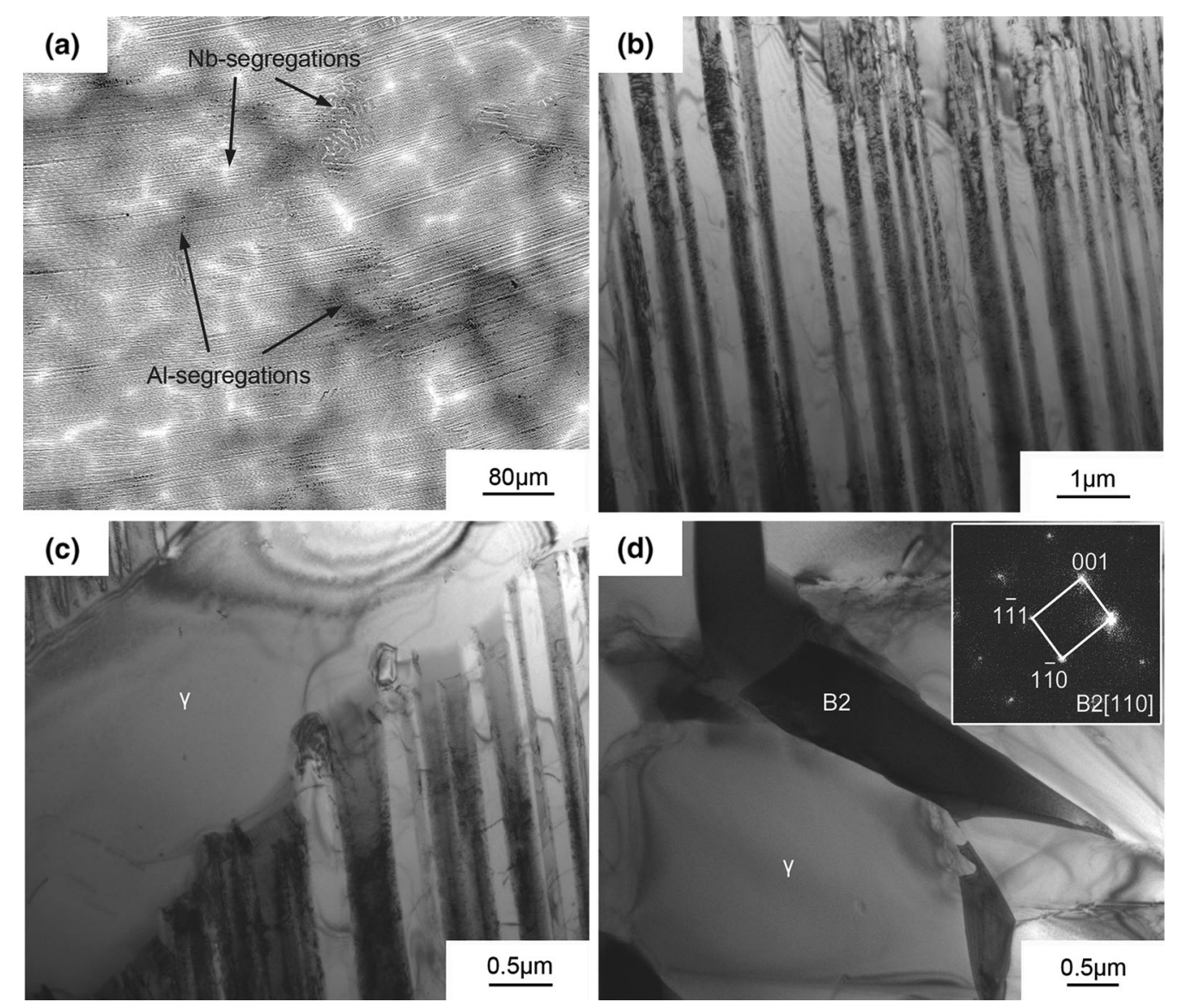

Fig. 1 Macrostructure a and microstructure of $\alpha_{2} / \gamma$ lamellae $\mathbf{b}, \gamma$ phase at lamellar boundaries $\mathbf{c}$ and B2 phase in lamellar colony $\mathbf{d}$ in the as-cast $\mathrm{Ti}-46 \mathrm{Al}-8 \mathrm{Nb}$ alloy

strain, showing dynamic recrystallization characteristic. With the increase in temperature and the decrease of strain rate, the flow stress decreases. At temperature of $1250{ }^{\circ} \mathrm{C}$ and strain rates of 0.01 and $0.001 \mathrm{~s}^{-1}$, the flow stress is not sensitive to deformation conditions and was almost steady.

Furthermore, parameter $Z$ was introduced to illustrate the dependence of flow stress on strain rate and temperature during hot deformation. It has been demonstrated that hot deformation is a process controlled by thermal activation which is frequently described by Eqs. (1) and (2). These equations are suitable for low stress regime $(\alpha \sigma<$ $0.8)$ and high stress regime $(\alpha \sigma>1.2)$, respectively,

$Z=\exp (Q /(R T))=A^{\prime} \sigma_{\mathrm{p}}^{n \prime}$,

$Z=\exp (Q /(R T))=A^{\prime \prime} \exp \left(\beta \sigma_{\mathrm{p}}\right)$,

while these equations can be combined into Eq. (3), which follows a hyperbolic sine relationship and can be applied over a wider range of stress $(0.3<\alpha \sigma<2.8)$,

$Z=\dot{\varepsilon} \exp (Q /(R T))=A\left[\sinh \left(\alpha \sigma_{\mathrm{p}}\right)\right]^{n}$,

where $Z$ is Zener-Hollomon parameter, $Q$ is the activation energy at high-temperature compression, $R$ is the universal gas constant, $n$ and $n^{\prime}$ are stress exponents, and $A, A^{\prime}, A^{\prime \prime}, \alpha$ and $\beta$ are constants, of which $\alpha=\beta / n^{\prime}$.

First, according to the true stress-true strain curves (Fig. 2) and converting Eqs. (1) and (2) into natural logarithmic form, the relationships between $\ln \sigma_{\mathrm{p}}-\ln (\dot{\varepsilon})$ and $\sigma_{\mathrm{p}}-\ln (\dot{\varepsilon})$ can be obtained, as shown in Fig. 3a, b. The measured constants of $n^{\prime}$ and $\beta$ were determined to be 5.43 and 0.013 , respectively, by linear fitting, and $\alpha$ was calculated to be $2.43 \times 10^{-3} \mathrm{MPa}^{-1}$.

Assuming that the hot compression temperature $T$ is a constant, $\ln (\dot{\varepsilon})$ and $\ln \left[\sinh \left(\alpha \sigma_{\mathrm{p}}\right)\right]$ will have a liner relationship such that the stress exponent $n$ for the alloy can be calculated by the following equation:

$n=\frac{\partial(\ln \dot{\varepsilon})}{\partial \ln \left[\sinh \left(\alpha \sigma_{\mathrm{p}}\right)\right]}$.

The relationship between $\ln \left[\sinh \left(\alpha \sigma_{\mathrm{p}}\right)\right]-\ln (\dot{\varepsilon})$ is shown in Fig. $3 \mathrm{c}$, and $n$ was estimated to be 4.04 . The $n$ values obtained at different deformation temperatures were 4.79 , $4.02,3.90$ and 3.44, respectively, in agreement with other alloys that lower $n$ values are usually observed at higher temperatures. The $n$ value above $1150{ }^{\circ} \mathrm{C}$ is not applicable 

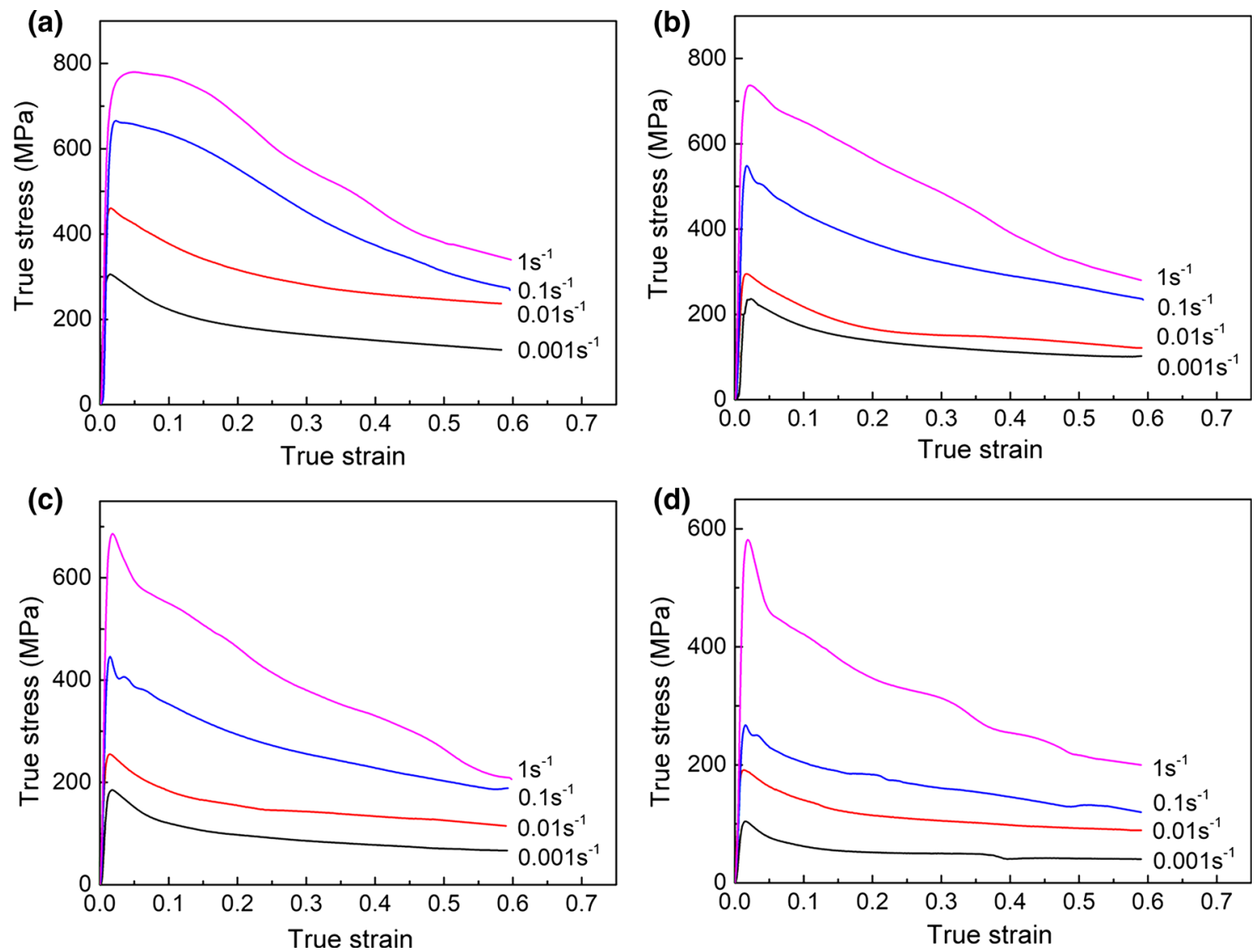

Fig. 2 True stress-strain curves at different strain rates obtained from the isothermal compression tests of Ti-46Al-8Nb alloy at: a $1100{ }^{\circ} \mathrm{C}$, b $1150{ }^{\circ} \mathrm{C}, \mathbf{c} 1200{ }^{\circ} \mathrm{C}, \mathbf{d} 1250{ }^{\circ} \mathrm{C}$

for dislocation-climb-controlled deformed alloys, $4.2<n<5.9$, which implied that another thermally controlled process played an important role at these compressive temperatures. The calculated values of $\alpha \sigma$ are in the range of $0.25-1.89$, which suggest that only hyperbolic sine relationship is suitable for calculation in this alloy.

The relationship, $\ln \left[\sinh \left(\alpha \sigma_{\mathrm{p}}\right)\right]-(1 / T)$, is shown in Fig. $3 \mathrm{~d}$, and if the strain rate $\dot{\varepsilon}$ is fixed, activation energy $(Q)$ is expressed by:

$Q=-n R \cdot \frac{\partial \ln \left[\sinh \left(\alpha \sigma_{\mathrm{p}}\right)\right]}{\partial(1 / T)}$.

According to the above calculation results, $Q$ was $446.91 \mathrm{~kJ} / \mathrm{mol}$.

The relationship between $Z$ parameter and peak stress in $\mathrm{Ti}-46 \mathrm{Al}-8 \mathrm{Nb}$ alloys is as follows:

$\sigma_{\mathrm{p}}=411.286 \sinh ^{-1}\left(3.107 \times 10^{-15} \cdot Z\right)^{0.254}$.

As depicted in Fig. 4, the data obtained between 1100 and $1250{ }^{\circ} \mathrm{C}$ fit well with the hyperbolic sine function, and $Z$ value increases with increasing peak stress.

The comparison of peak stress and activation energy values for different TiAl alloys is listed in Table 1. The
$Q$ value in our work is higher than that of $\mathrm{Ti}-45 \mathrm{Al}-7 \mathrm{Nb}-$ $0.3 \mathrm{~W}$, Ti-45Al-7Nb-0.4W and $\mathrm{Ti}-47 \mathrm{Al}-1 \mathrm{~V}$ alloys, but smaller than that of $\mathrm{Ti}-43.9 \mathrm{Al}-4.3 \mathrm{Nb}-(\mathrm{Mo}, \mathrm{B}, \mathrm{Si})$ alloy. It is noted that $Q$ values increase with increasing Nb content and lower $\mathrm{Al}$ content. This is consistent with previous studies [24-28]. Meanwhile, the peak stress of 255.2 $\mathrm{MPa}$ in our work is obviously higher than that of other TiAl alloys at $1200{ }^{\circ} \mathrm{C}$ and strain rate of $0.01 \mathrm{~s}^{-1}$, which is most likely to be related to high $\mathrm{Nb}$ content. In high $\mathrm{Nb}$-containing alloys, solute $\mathrm{Nb}$ atoms would increase the elastic distortion energy, affecting dislocation thermal diffusion and increasing the activation energy [29]. The reasons may directly determine the characteristics of true stress-true strain curves in our work. Furthermore, the higher deformation activation energy and flow stress suggest that the alloy is difficult to be deformed, because it needs more external energy to activate the dislocations and other substructures. Consequently, the microstructural evolution at various $Z$ values and identification of hot deformation mechanisms are significant and are addressed below. 

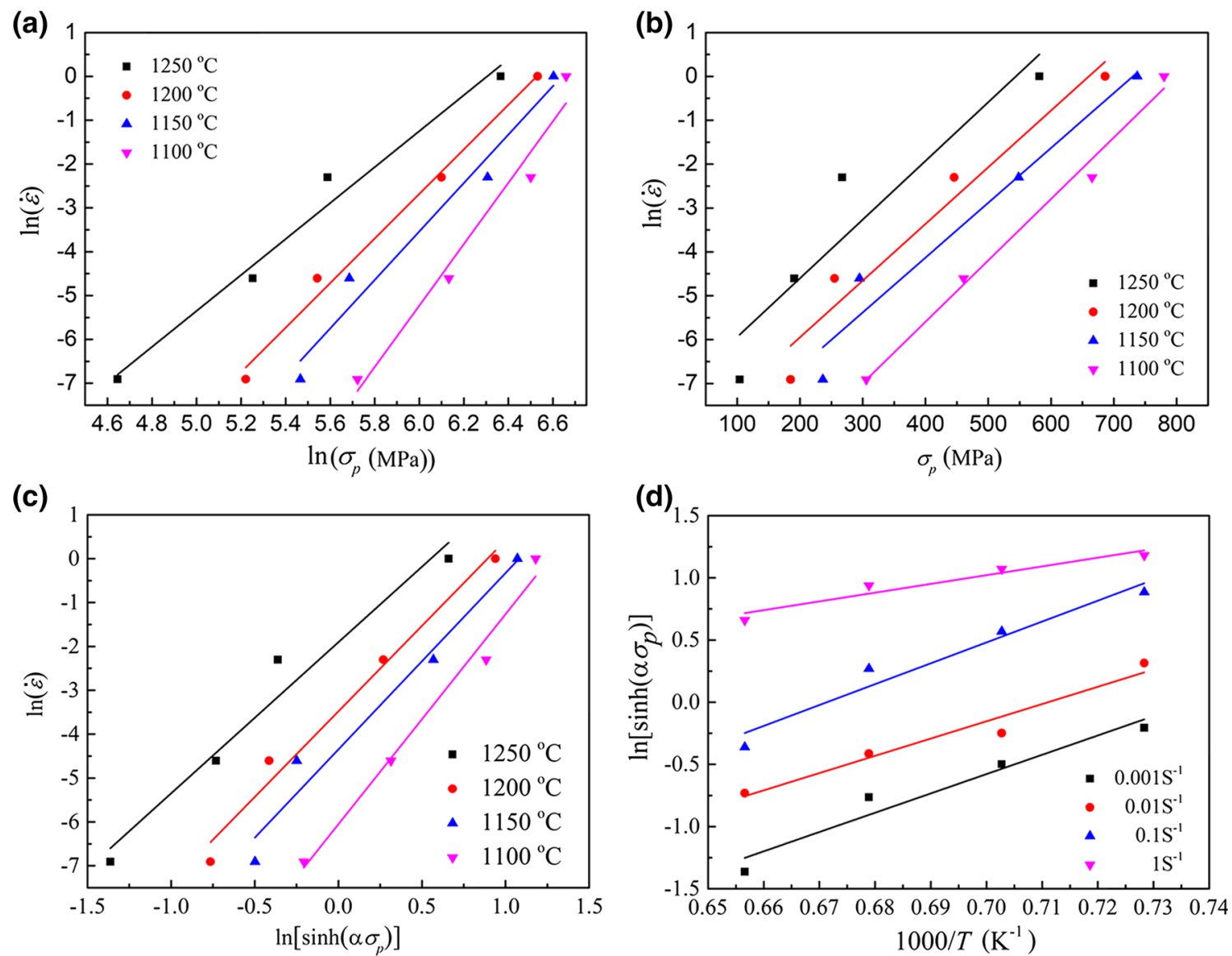

Fig. 3 Relationship between peak stress and deformation conditions for the Ti-46Al-8Nb alloy: a $\ln \sigma_{\mathrm{p}}-\ln (\dot{\varepsilon})$, b $\left.\sigma_{\mathrm{p}}-\ln (\dot{\varepsilon})\right)$, c $\ln \left[\sinh \left(\alpha \sigma_{\mathrm{p}}\right)\right]-\ln (\dot{\varepsilon}), \mathbf{d} 1000 / T-\ln \left[\sinh \left(\alpha \sigma_{\mathrm{p}}\right)\right]$

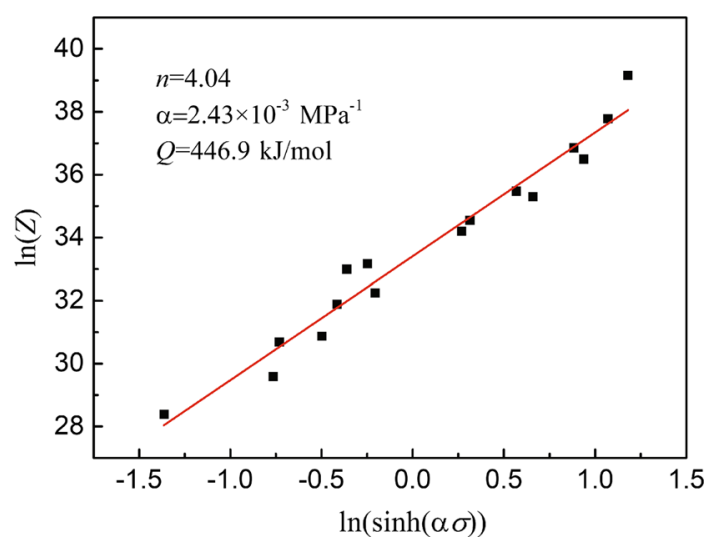

Fig. 4 Relationship between peak stress and $Z$ parameter

\subsection{Hot Deformation Microstructure}

Figure 5 shows hot deformation microstructural evolution with decreasing $\ln Z$ values at different temperatures and strain rates for Ti-46Al-8Nb alloy. It may be noted that inhomogeneous microstructure was observed, with alternating deformed ribbons of Al-rich (dark region) at grain boundaries and $\mathrm{Nb}$-rich (light region) at the center of lamellae.

Figure $5 \mathrm{a}, \mathrm{b}$ shows a typical ribbon structure with elongated $\alpha_{2} / \gamma$ lamellae and fine $\gamma$ grains at the grain boundaries (dark Al-segregated region). At true strain of 0.6 at lower temperature and higher strain rate, the lamellar colonies showed a "Z"-shape kink or elongated morphology along the direction of normal to the stress in Fig. 5a. Dynamic recrystallization (DRX) could only be observed in Al-rich region. With decreasing $\ln Z$ value, the $\alpha_{2} / \gamma$ interfaces became normal to the compression stress and were further decomposed to some extent. Localized DRX can be observed in $\mathrm{Al}$-segregated region and $\mathrm{Nb}$-segregated region, as shown in Fig. 5b, c. Moreover, the $\alpha_{2} / \gamma$ lamellae colonies and solute segregation disappeared gradually with decreasing $\ln Z$. With further decrease in $\ln Z$ in Fig. 5 d, e, the elongated $\alpha_{2} / \gamma$ lamellae decomposed into multiple structures with equiaxed $\alpha_{2} / \gamma$ lamellae, $\gamma$-and $\alpha$-phase. The locally deformed $\mathrm{Nb}$ segregation ribbon gradually disappeared and was occupied by DRX grains, while the Alsegregated region was composed of coarse DRX grains and massive $\gamma$ phase, as shown in Fig. 5d, e. Finally, the coarse 
Table 1 Activation energy and peak stress of TiAl alloys during high-temperature compression deformation [11, 24-26]

\begin{tabular}{lllccc}
\hline Composition (at.\%) & Initial microstructure & $T\left({ }^{\circ} \mathrm{C}\right)$ & $\dot{\varepsilon}\left(\mathrm{s}^{-1}\right)$ & $\sigma_{\mathrm{p}}(\mathrm{MPa})$ & $Q(\mathrm{~kJ} / \mathrm{mol})$ \\
\hline Ti-45Al-7Nb-0.3W & Near $\gamma$, HIP & $1050-1200$ & $1 \times 10^{0}-1 \times 10^{-3}$ & 140 & 414 \\
Ti-47Al-1V & Nearly lamellar (IM) & $1000-1200$ & $1 \times 10^{0}-1 \times 10^{-3}$ & 125 & 404 \\
Ti-43.9Al-4.3Nb-(Mo, B) & Nearly lamellar, HIP & $1100-1250$ & $1 \times 10^{0}-1 \times 10^{-2}$ & 60 & 540.3 \\
Ti-45Al-7Nb-0.4W & Nearly lamellar (PM) & $1000-1200$ & $1 \times 10^{-1}-1 \times 10^{-3}$ & 160 & 420 \\
Ti-46Al-8Nb [this work] & Nearly lamellar (IM) & $1100-1250$ & $1 \times 10^{0}-1 \times 10^{-3}$ & 255 & 446.9
\end{tabular}

The peak stress was obtained at $1200{ }^{\circ} \mathrm{C}$ and $0.01 \mathrm{~s}^{-1}$
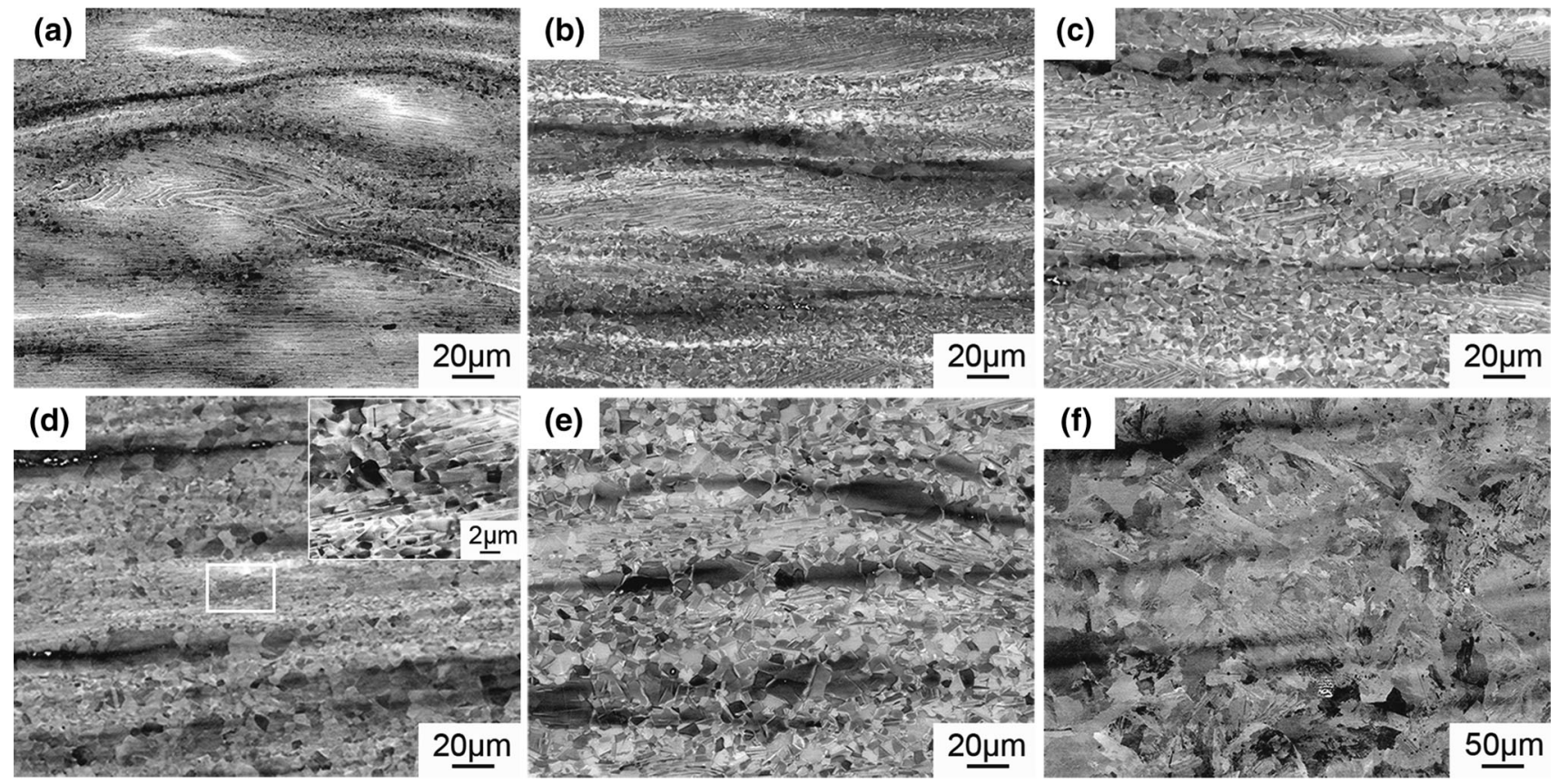

Fig. 5 Microstructures of hot-deformed $\mathrm{Ti}-46 \mathrm{Al}-8 \mathrm{Nb}$ alloys at different $\ln Z$ values: $\mathbf{a} \ln Z=36.85\left(1100{ }^{\circ} \mathrm{C} / 0.1 \mathrm{~s}^{-1}\right)$, b $\ln Z=33.17$ $\left(1150{ }^{\circ} \mathrm{C} / 0.01 \mathrm{~s}^{-1}\right), \mathbf{c} \ln Z=31.89\left(1200{ }^{\circ} \mathrm{C} / 0.01 \mathrm{~s}^{-1}\right), \mathbf{d} \ln Z=30.69\left(1250{ }^{\circ} \mathrm{C} / 0.01 \mathrm{~s}^{-1}\right)$ and the insertion shows the detailed view of the white box, e $\ln Z=29.58\left(1200{ }^{\circ} \mathrm{C} / 0.001 \mathrm{~s}^{-1}\right), \mathbf{f} \ln Z=28.39\left(1250{ }^{\circ} \mathrm{C} / 0.001 \mathrm{~s}^{-1}\right)$

DRX grains and massive $\gamma$ phase were observed with lowest $\ln Z$ value in hot-deformed $\mathrm{Ti}-46 \mathrm{Al}-8 \mathrm{Nb}$ alloy, as shown in Fig. $5 f$.

The above results indicated the local flow softening with alternating Al-rich ribbon and $\mathrm{Nb}$-rich ribbon in the hotdeformed $\mathrm{Ti}-46 \mathrm{Al}-8 \mathrm{Nb}$ alloy. The solute segregations resulted in severe microstructural inhomogeneity, and the coarse DRX structure with massive $\gamma$ phase was obtained at high temperature and low strain rate. This inhomogeneity is different from the previous studies on hot-deformed microstructure of Ti-44Al-8Nb alloy by Zhou et al. [28] and $\mathrm{Ti}-43.9 \mathrm{Al}-4.3 \mathrm{Nb}-0.9 \mathrm{Mo}-0.1 \mathrm{~B}-0.4 \mathrm{Si}$ alloy by $\mathrm{Li}$ et al. [27], which had the multiphase microstructure of $\gamma, \alpha, \mathrm{B} 2$ equiaxed crystals and retained $\alpha_{2} / \gamma$ lamellae. A detailed evolution of microstructure in the hot-deformed $\mathrm{Ti}-46 \mathrm{Al}-$ $8 \mathrm{Nb}$ alloy is presented below.

\subsection{Flow Localization and Deformation Mechanism}

The local flow softening mentioned above can be closely related to high solute segregation in Ti-46Al-8Nb alloy.

Figure 6 shows the evolution of hot-deformed microstructure in $\mathrm{Al}$-rich region at the grain boundary with different $\ln Z$ values. The dark elongated ribbon containing a number of DRX grains with the size of less than $2 \mu \mathrm{m}$ at high $\ln Z$ value was observed, as shown in Fig. 6a. Furthermore, the DRX grains in Al-segregated region grew gradually with the decrease in $\ln Z$, and $\gamma$ grains in the Alsegregated region grew rapidly from 1 to $40 \mu \mathrm{m}$, as shown in Fig. 6a-d. Finally, grown DRX grains and massive $\gamma$ phase were present in the Al-segregated region at the grain boundary. The above results can be attributed to the fact that $\gamma$ phase always recrystallized first at the grain 

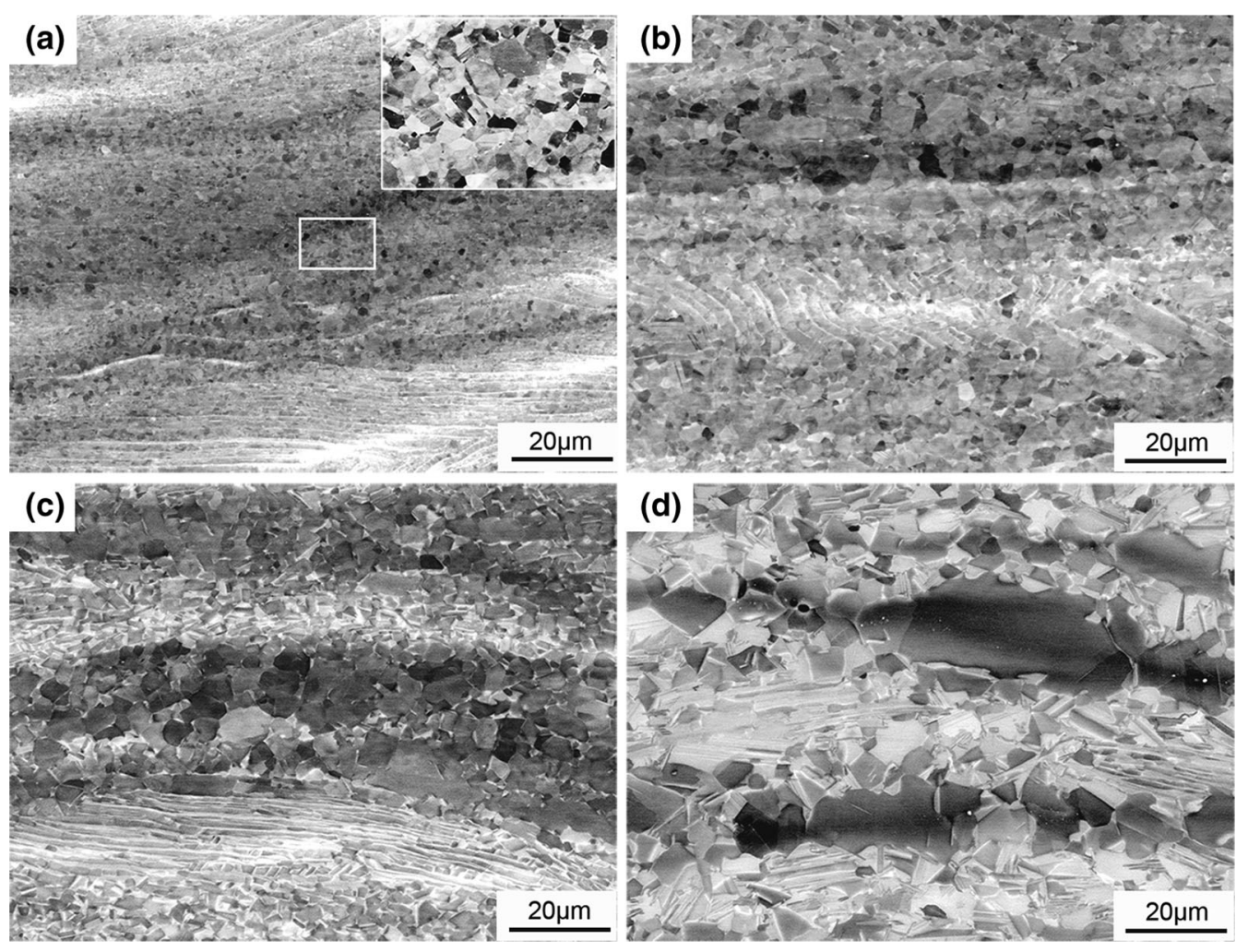

Fig. 6 Microstructures of Al-segregated region in the hot-deformed Ti-48Al-8Nb alloy with the different $Z$ values: a $\ln Z=37.77\left(1150{ }^{\circ} \mathrm{C} /\right.$ $\left.1 \mathrm{~s}^{-1}\right)$ and the inset shows a detailed view of the white box, $\mathbf{b} \ln Z=35.47\left(1150{ }^{\circ} \mathrm{C} / 0.1 \mathrm{~s} \mathrm{~s}^{-1}\right), \mathbf{c} \ln Z=31.89\left(1200{ }^{\circ} \mathrm{C} / 0.01 \mathrm{~s}^{-1}\right), \mathbf{d} \ln Z=29.58$ $\left(1200{ }^{\circ} \mathrm{C} / 0.001 \mathrm{~s}^{-1}\right)$

boundary. The fine DRX grains would accelerate the crystal boundary migration and grain rotation, which produces stress concentration, leading to local softening at the grain boundary. The softening can be further facilitated by high Al-enrichment, which promotes $L\left(\alpha_{2} / \gamma\right) \rightarrow \gamma$ transition under temperature and deformation stress, as well as $\mathrm{Nb}$ solution, which decreases the stacking fault energy of $\gamma$ phase. Finally, completely DRX grains are obtained first in Al-segregated region of the hot-deformed $\mathrm{Ti}-46 \mathrm{Al}-8 \mathrm{Nb}$ alloy.

The detailed substructure and deformation mechanism were investigated in the $\gamma$ phase in $\mathrm{Al}$-segregated region by TEM as shown in Fig. 7. The dislocation movement and pileup in $\gamma$ grains can be observed in Fig. 7a. It is known that deformation of $L 1_{0}$ structure $\gamma$-TiAl always occurs on $\{111\}$ planes by glide of ordinary dislocations with Burgers vector $\mathbf{b}=1 / 2<110$ ] and super dislocations with Burgers vector $\mathbf{b}=<101]$ and $1 / 2<112$ ], respectively [30]. These processes occur when there is sufficient thermal activation to allow long-range diffusion of dislocations. The comparatively low stacking fault energy of $\gamma$ phase with high $\mathrm{Nb}$ in solution makes the dislocations difficult to cross slip or climb, which promotes dislocation pileup and sub-grain formation in $\gamma$ phase.
In addition, extensive twinning with different thickness was observed in $\gamma$ phase. Figure $7 \mathrm{~b}$, c shows mechanical twins or thin intersecting twins with fixed angle of about $70^{\circ} 22^{\prime}$. These twins were identified to be twinning systems of type $\mathbf{b}=1 / 6<11 \overline{2}]$ that propagate on oblique $\{111\}$ planes [31], and the different morphologies are viewed from different [111] and [110] zone axes, respectively. Although the mode of twin nucleation in Ti-46Al-8Nb alloy is not clarified at this time, we speculate that it is related to the very low stack fault energy of the alloy. The stacking faults easily extend and partial dislocations increase rapidly under the deformation conditions, which would activate twinning. The deformation of the twins and the interaction between the twins and dislocations promote nucleation of DRX $\gamma$ grains, as shown in Fig. 7d.

From the above results, the low-temperature brittleness of TiAl alloys is triggered by the small extent of operating slip systems in $\gamma$ phase at low temperature, while more operative slip systems in $\gamma$-TiAl, comprising dislocations and super dislocations, are easily activated during high strain energy deformation at elevated temperature and consequently promote twinning and dynamic recrystallization.

Figure 8 shows detailed microstructure evolution and flow softening in the $\mathrm{Nb}$-segregated region in the hot- 

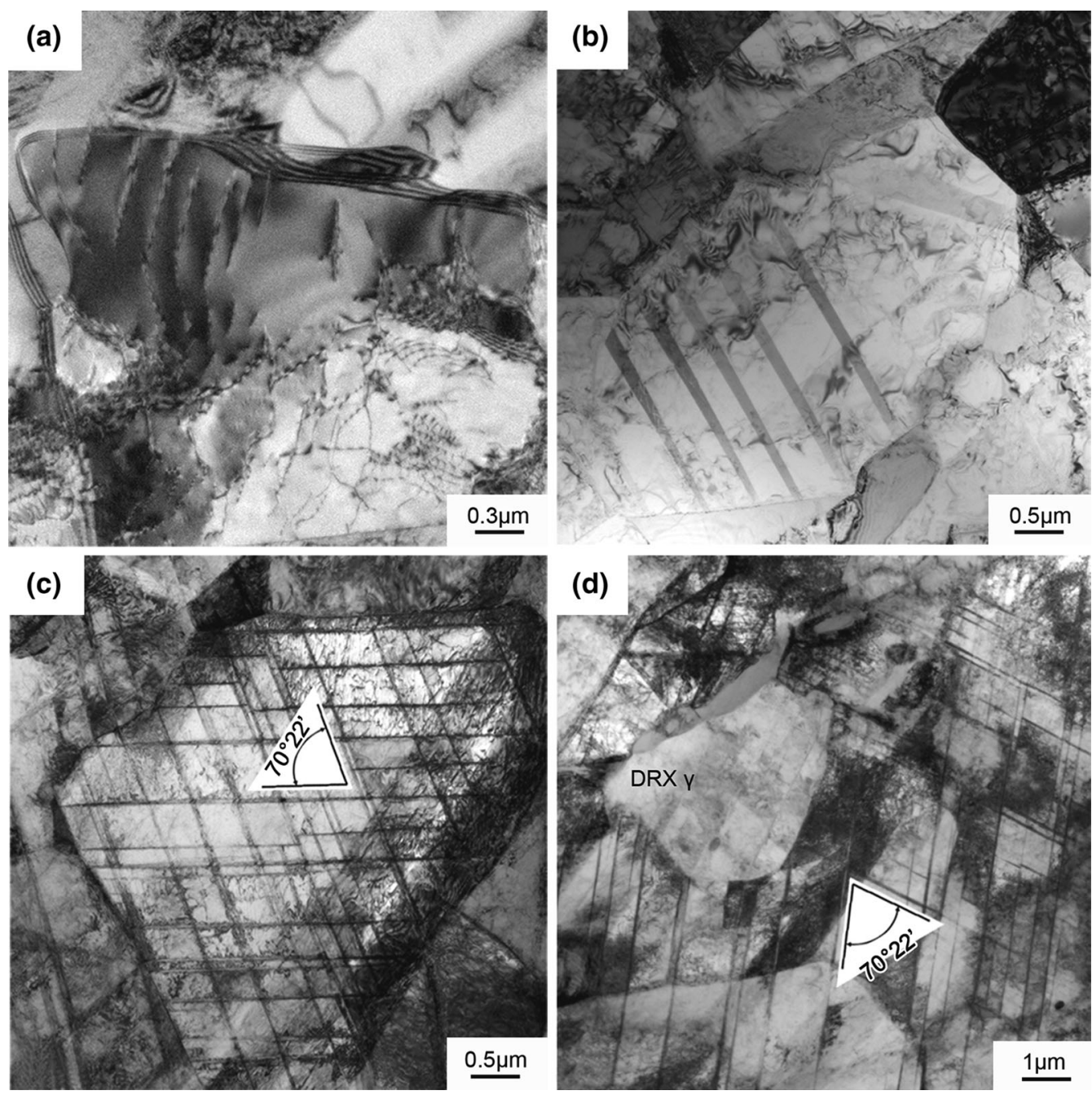

Fig. 7 TEM micrographs of deformed $\gamma$ phase in Al-segregated region. $\mathbf{a} \gamma$ sub-grains induced by dislocation movement, $\mathbf{b}$ mechanical twins in $\gamma$ grains, $\mathbf{c}$ dislocations pileup at the boundaries and intersection of the twins in $\gamma$ grains, $\mathbf{d}$ DRX $\gamma$ grains induced by $1 / 6<11 \overline{2}]\{111\}$ twins

deformed $\mathrm{Ti}-46 \mathrm{Al}-8 \mathrm{Nb}$ alloy. In contrast to the Al-rich region, the recrystallized grains were lacking, while a number of bending $\alpha_{2} / \gamma$ colonies can be observed, as shown in broken-line boxes of Fig. 8a, b, which shows typical shear deformation around the $\mathrm{Nb}$-segregated region. The $\beta$ stabilizer $\mathrm{Nb}$ enrichment with $\mathrm{B} 2$-phase precipitation in the $\alpha_{2} / \gamma$ colonies can be observed, and the soft bcc-structure B2 phase with multiple-slip systems at high temperature may promote local flow around $\mathrm{Nb}$-segregated region, leading to bending of $\alpha_{2} / \gamma$ lamellae. Simultaneously, the local shear strain around the $\mathrm{Nb}$ enrichment may promote $\alpha_{2} / \gamma$ colonies to DRX process of $\gamma$ and $\alpha$ grains, as shown in Fig. 8b, which accelerates the decomposition of the $\alpha_{2} / \gamma$ lamellar structure.

Additionally, Fig. 8c, d shows detailed morphologies of bending $\alpha_{2} / \gamma$ colonies. The broad $\gamma$ lath, thin $\alpha_{2}$ lath and the DRX grains can be observed at the kinking point, which shows the breakdown of $\alpha_{2} / \gamma$ lamellae to equiaxed $\alpha$ and $\gamma$ grains, under the deformation stress and temperature. DRX grains in broad $\gamma$ lath can be observed to be $2-6 \mu \mathrm{m}$, and the growth of recrystallized grains may destroy the lamellar structure, as shown in the dotted circle in Fig. 8c, d. From the above results, the bcc soft B2 phase from $\mathrm{Nb}$ segregation can easily induce local shear strain in lamellar colony at the deformation temperature, which promotes $\alpha_{2} /$ $\gamma$ lamellar colonies to bend and break down. Therefore, appropriate addition of $\mathrm{Nb}$ in TiAl alloy may be beneficial to fine grains and homogeneous microstructure of the hotdeformed TiAl alloy.

The retained microstructure of bending lamellae is further illustrated by electron backscattered diffraction (EBSD), as shown in Fig. 9. The multiple morphologies including bending $\alpha_{2} / \gamma$ lamellae with $80.3^{\circ}$, recrystallized $\gamma$ lath and equiaxed grains ( $\gamma$ and $\alpha_{2}$ phases) at the bending points are observed in image quality (IQ) map, as shown in Fig. 9a. The $\gamma$-phase laths with low stacking fault energy 

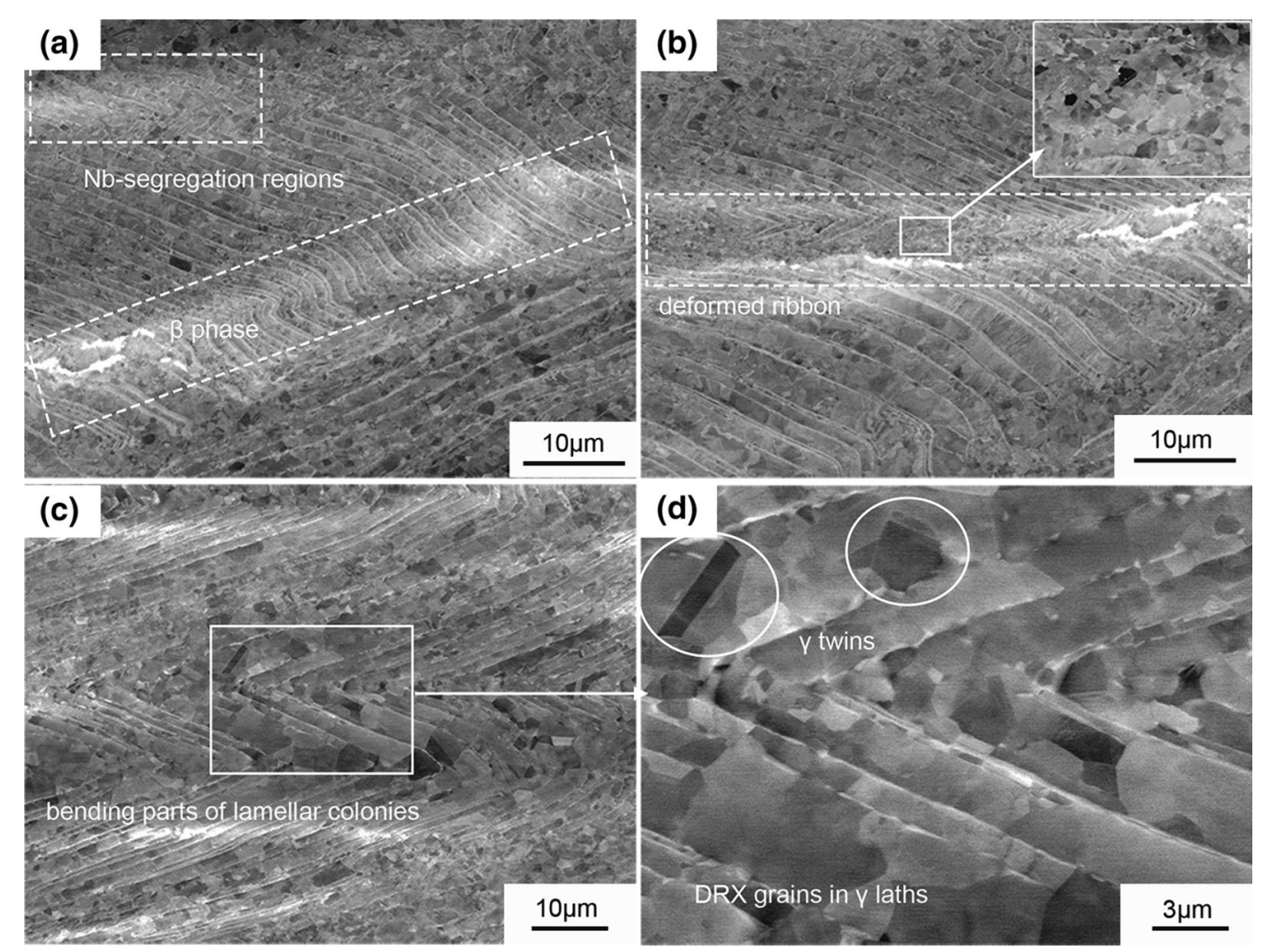

Fig. 8 Microstructures in Nb-rich region in hot-deformed Ti-46Al-8Nb alloy. a bending lamellar and elongated B2 phase, $\mathbf{b}$ deformation ribbon in $\mathrm{Nb}$-enriched region and the inset shows detailed view of white box, $\mathbf{c}, \mathbf{d}$ the bending lamellae and detailed microstructure

are first broken by the recrystallized grains with high-angle grain boundary (marked with black line) in Fig. 9b. Simultaneously, discontinuous and thin $\alpha_{2}$ laths are observed, resulting from $\alpha \rightarrow \gamma$ transition and the growth of recrystallized $\gamma$ grains. Furthermore, the equiaxed $\alpha$ and $\gamma$ grains exist at the bending point mainly due to the growth of recrystallized $\gamma$ phase and decomposition of $\alpha$ lamellae. Additionally, the grain orientation spread in Fig. 9c indicates that the bending lamellae has high local strain with high dislocation density and distortion energy (red color region), while the equiaxed grain region has low distortion because of stress release through phase transition and recrystallization. The lamellae with high distortion energy would be subsequently destroyed if the recrystallization is more sufficient. Simultaneously, the severe torsion during the deformation process results in the different lamellar orientations between the upper part and lower part of the selected region in Fig. 9d. Generally, the recrystallization and growth of $\gamma$ phase accompany $\alpha \rightarrow \gamma$ transition and breaking of $\alpha_{2} / \gamma$ lamellar structure, especially bending lamellae with high distortion energy, followed by the decomposition of $\alpha_{2} / \gamma$ lamellar to equiaxed $\gamma$ and $\alpha$ grains. This also promotes flow softening process for the $\alpha_{2} / \gamma$ lamellar structure [32].

Figure 10 shows TEM micrographs describing the evolution of $\alpha_{2} / \gamma$ lamellar structure in hot-deformed Ti$46 \mathrm{Al}-8 \mathrm{Nb}$ alloy. Under deformation stress and temperature, extensive $\gamma$ twins and dislocations are generated in lamellar colonies in Fig. 10a, which may be regarded as the prior condition of twinning and dislocation-induced dynamic recrystallization. Simultaneously, the recrystallized $\gamma$ grain growth and $\alpha \rightarrow \gamma$ transition break the $\alpha_{2} / \gamma$ lamellae, as shown by dotted region in Fig. 10a, and then the multiple-phase structure retained $\alpha_{2} / \gamma$ lamellae, recrystallized $\alpha, \gamma$ grains is obtained in Fig. 10b, especially in the bending lamellar region. The breakdown of the $\alpha_{2} / \gamma$ lamellae contributes to stress relaxation, while the retained lamellae are accompanied by high dislocation density and distortion energy, as shown by the bright-field image in Fig. 10c. Moreover, the majority of $\alpha_{2} / \gamma$ lamellae can 

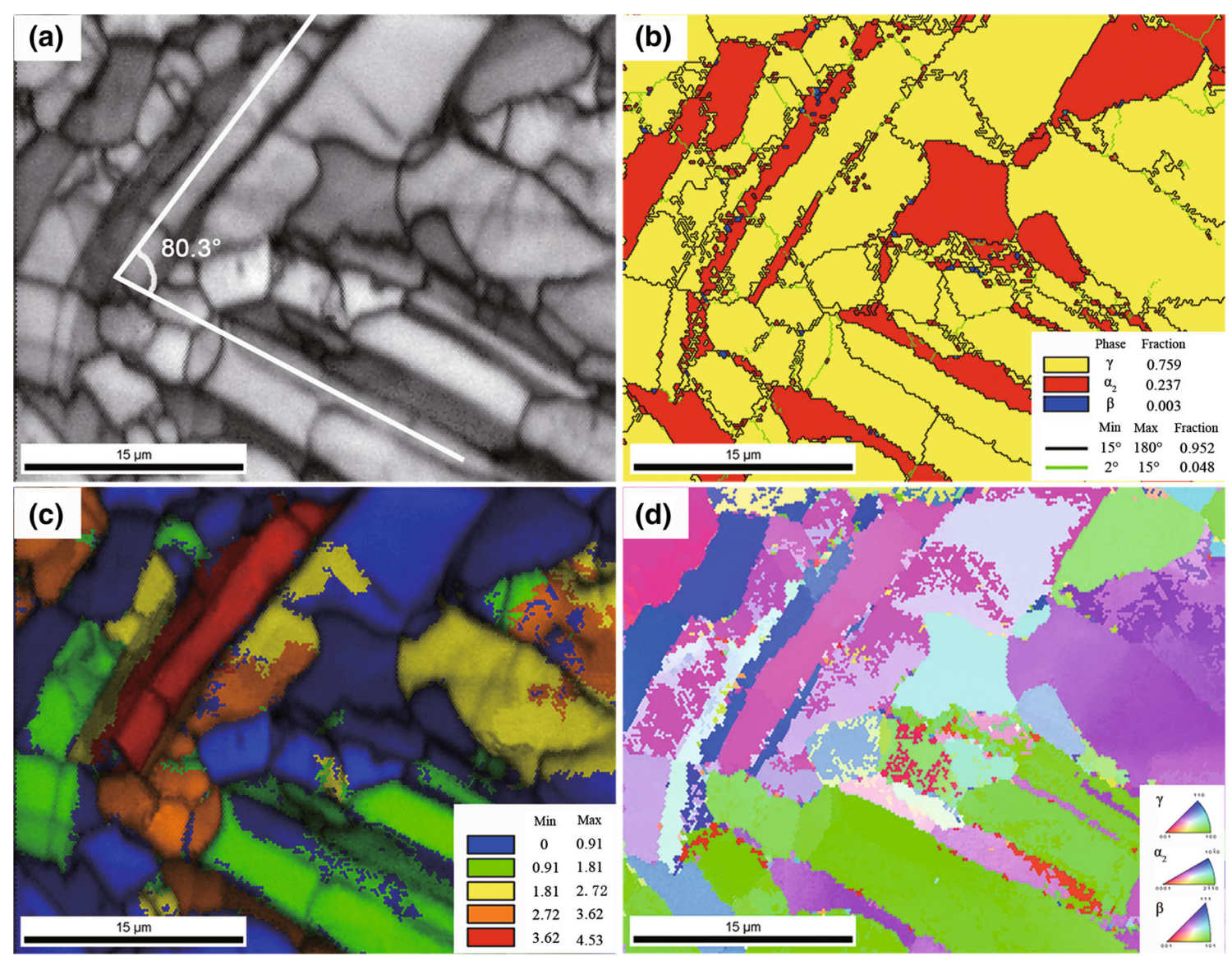

Fig. 9 EBSD images of the evolution of bending lamellar colony of Ti-46Al-8Nb alloy. a Image quality (IQ) map, b phase map overlaid with high- and low-angle grain boundaries, $\mathbf{c}$ grain orientation spread (GOS) map, $\mathbf{d}$ inverse pole figure (IPF) map

decompose into equiaxed $\gamma$ and $\alpha$ grains, and pileup of dislocations at the grain boundaries (Fig. 10d).

In the hot-deformed TiAl alloys, the retained $\alpha_{2} / \gamma$ lamellae with high resistance to deformation leads to flow anisotropy. Semiatin et al. [33] reported that the remnant lamellar colonies deteriorate the thickness gage of rolled sheets because of high flow stress. It is common that the inhomogeneous microstructure with coarse retained $\alpha_{2} / \gamma$ lamellae leads to wide scatter in mechanical properties in forged, extruded and rolled TiAl alloys [34-36], which should be eliminated by improved hot deformation process and subsequent heat treatment. In the case of Ti-46Al- $8 \mathrm{Nb}$ alloy with peritectic reaction, the retained $\alpha_{2} / \gamma$ lamellae can be aggravated by severe localized flow softening in the high Al-segregated region at the grain boundary, while the $\mathrm{Nb}$-segregated region with soft B2 phase can promote the breakdown of kinked $\alpha_{2} / \gamma$ lamellar. Thus, homogeneous microstructure during the hot-deformed process can be 

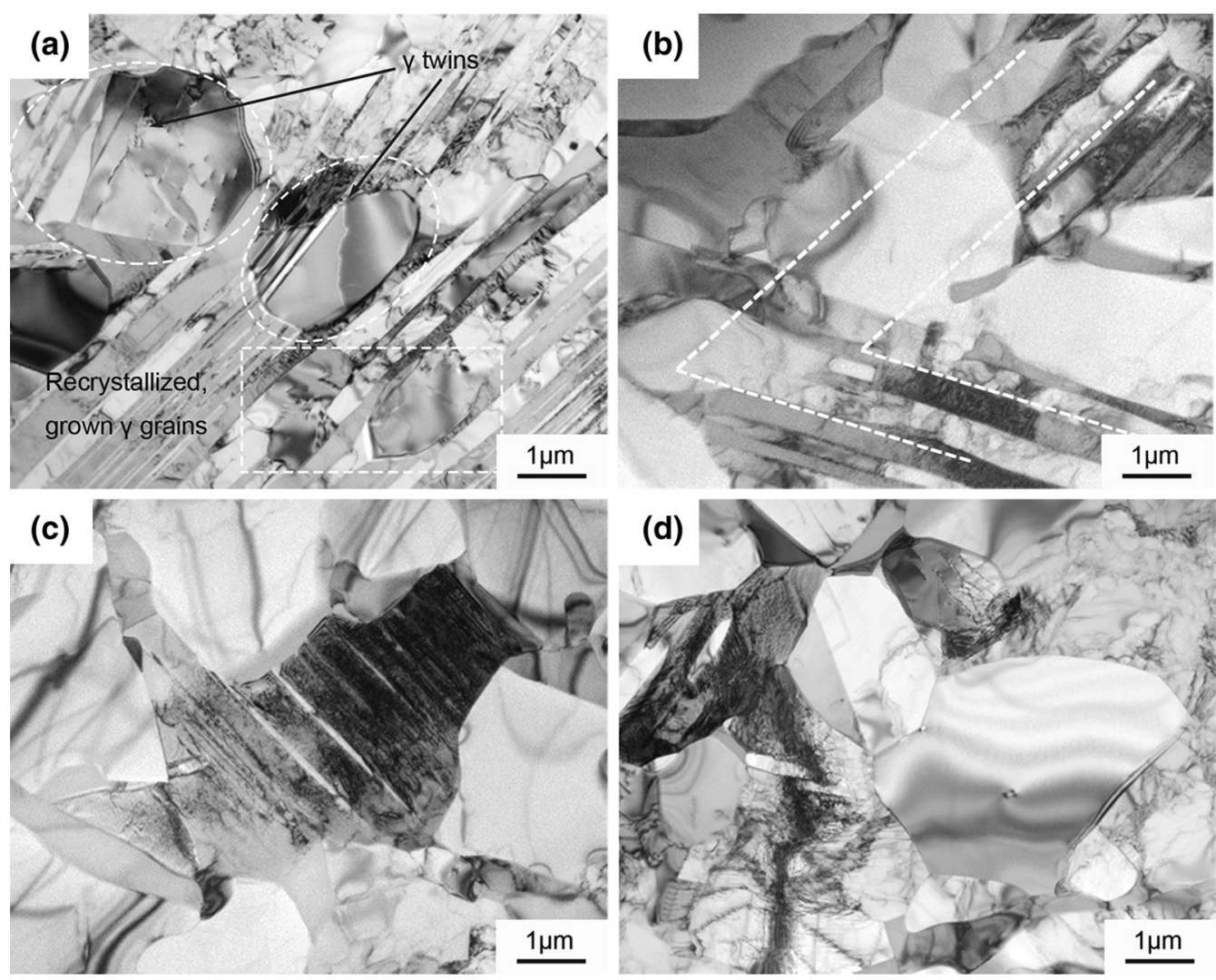

Fig. 10 Bright-field TEM images of the microstructures of hot-deformed Ti-46Al-8Nb alloy: $\mathbf{a} \gamma$ twins and growth of $\gamma$ grains, $\mathbf{b}$ multiple-phase structure in the kink region, $\mathbf{c}$ retained lamellae, $\mathbf{d}$ recrystallized grains and sub-grain structure

obtained in TiAl alloys with high $\mathrm{Nb}$ content and low $\mathrm{Al}$ segregation.

\section{Conclusions}

The hot deformation behavior and microstructural characteristics of hot-deformed $\mathrm{Ti}-46 \mathrm{Al}-8 \mathrm{Nb}$ alloy were studied, and the following conclusions were obtained:

(1) The true stress-strain curves of hot-deformed Ti$46 \mathrm{Al}-8 \mathrm{Nb}$ alloy exhibited typical work hardening and flow softening, and the peak stress was described by a $Z$ parameter and the following equation: $\sigma_{\mathrm{p}}=411.286 \sinh ^{-1}\left(3.107 \times 10^{-15} \cdot Z\right)^{0.254}$. The activation energy $(Q)$ of the hot-deformed Ti$46 \mathrm{Al}-8 \mathrm{Nb}$ alloy was calculated to be $446.9 \mathrm{~kJ} / \mathrm{mol}$.
(2) The inhomogeneous microstructure was observed in hot-deformed $\mathrm{Ti}-46 \mathrm{Al}-8 \mathrm{Nb}$ alloy, which was closely related to the localized flow in solute $\mathrm{Al}$ - and $\mathrm{Nb}$-segregated regions. Al segregation promoted localized flow softening due to recrystallization of $\gamma$ phase with low stacking fault energy, as well as the $L\left(\alpha_{2} / \gamma\right) \rightarrow \gamma$ transition under the deformation conditions. $\mathrm{Nb}$ segregation with soft $\mathrm{B} 2$ phase induced bending lamellar structure and breakdown of $\alpha_{2} / \gamma$ lamellar colony.

(3) The $\gamma$-phase recrystallization and twinning, the kinked $\alpha_{2} / \gamma$ lamellar and $L\left(\alpha_{2} / \gamma\right) \rightarrow$ equiaxed $\alpha+\gamma$ transition, soft $\beta$ phase and dislocation slip were the main softening mechanisms. Homogeneous microstructure during the hot-deformed process can be obtained in TiAl alloys containing high $\mathrm{Nb}$ and low $\mathrm{Al}$ segregation. 
Acknowledgements This project was supported by the National Key Research and Development Program of China (No. 2016YFB0301201), the National Natural Science Foundation of China (Nos. 51504060, 51301140) and the Fundamental Research Funds for the Central Universities (No. N160713001).

\section{References}

[1] F. Appel, M. Oehring, R. Wagner, Intermetallics 8, 1283 (2000)

[2] J.J. Xin, L.Q. Zhang, G.W. Ge, J.P. Lin, Mater. Des. 107, 406 (2016)

[3] G.H. Liu, Z.D. Wang, T.L. Fu, Y. Li, H.T. Liu, T.R. Li, M.N. Gong, G.D. Wang, J. Alloys Compd. 650, 45 (2015)

[4] H.Z. Niu, Y.Y. Chen, S.L. Xiao, F.T. Kong, C.J. Zhang, Intermetallics 19, 1767 (2011)

[5] W.Y. Gui, G.J. Hao, Y.F. Liang, F. Li, X. Liu, J.P. Lin, Appl. Surf. Sci. 389, 1161 (2016)

[6] L. Cheng, H. Chang, B. Tang, H.C. Kou, J.S. Li, Adv. Mater. Res. 510, 723 (2012)

[7] Z.C. Liu, J.P. Lin, S.J. Li, G.L. Chen, Intermetallics 10, 653 (2002)

[8] H.Z. Niu, F.T. Kong, Y.Y. Chen, F. Yang, J. Alloys Compd. 509, 10179 (2011)

[9] B. Liu, Y. Liu, Y.P. Li, W. Zhang, A. Chiba, Intermetallics 19, 1184 (2011)

[10] H. Clemens, W. Wallgram, S. Kremmer, V. Güther, A. Otto, A. Bartels, Adv. Eng. Mater. 10, 707 (2008)

[11] B. Liu, Y. Liu, W. Zhang, J.S. Huang, Intermetallics 19, 154 (2011)

[12] X.J. Xu, L.H. Xu, J.P. Lin, Y.L. Wang, Z. Lin, G.L. Chen, Intermetallics 13, 337 (2005)

[13] G.L. Chen, X.J. Xu, Z.K. Teng, Y.L. Wang, J.P. Lin, Intermetallics 15, 625 (2007)

[14] Z.W. Huang, Scr. Mater. 52, 1021 (2005)

[15] X.J. Xu, L. Song, Y.F. Liang, J.P. Lin, T. Mater, Heat Treat. 36, 79 (2015)
[16] Y.F. Liang, X.J. Xu, L.P. Lin, Rare Met. 35, 15 (2016)

[17] Z.F. Xu, X.J. Xu, J.P. Lin, Y. Zhang, Y.L. Wang, Z. Lin, G.L. Chen, J. Aeronaut. Mater. 27, 28 (2007)

[18] Z.F. Xu, X.J. Xu, J.P. Lin, Y. Zhang, Y.L. Wang, Z. Lin, G.L. Chen, J. Mater. Eng. 9, 42 (2007)

[19] H.Z. Li, Z. Li, W. Zhang, Y. Wang, Y. Liu, H.J. Wang, J. Alloys Compd. 508, 359 (2010)

[20] Z.H. Huang, Intermetallics 13, 245 (2005)

[21] T.T. Cheng, Intermetallics 7, 995 (1999)

[22] T.T. Cheng, M.H. Loretto, Acta Mater. 46, 4801 (1998)

[23] G.H. Liu, X.Z. Li, Y.Q. Su, D.M. Liu, J.J. Guo, H.Z. Fu, J. Alloys Compd. 541, 275 (2012)

[24] H.Y. Kim, W.H. Sohn, S.H. Hong, Mater. Sci. Eng., A 251, 216 (1998)

[25] S.S. Li, X.K. Su, Y.F. Han, X.J. Xu, G.L. Chen, Intermetallics 13, 323 (2005)

[26] S.W. Zeng, A.M. Zhao, H.T. Jiang, X.N. Ding, D. Peng, Mater. Sci. Eng., A 661, 160 (2016)

[27] J.B. Li, Y. Liu, B. Liu, Y. Wang, P. Cao, C.X. Zhou, C.J. Xiang, Y.H. He, Intermetallics 52, 49 (2014)

[28] L. Cheng, X.Y. Xue, B. Tang, H.C. Kou, J.S. Li, Intermetallics 49, 23 (2014)

[29] Y. Wang, Y. Liu, G.Y. Yang, J.B. Li, B. Liu, J.W. Wang, H.Z. Li, Mater. Sci. Eng., A 577, 210 (2013)

[30] R.M. Imayev, V.M. Imayev, M. Oehring, F. Appel, Metall. Mater. Trans. A 36, 859 (2005)

[31] W.J. Zhang, F. Appel, Mater. Sci. Eng., A 334, 59 (2002)

[32] Z.G. Lu, J. Wu, Guo P. Ru, L. Xu, R. Yang, Acta Metall. Sin. (Engl. Lett.) 30, 621 (2017)

[33] S.L. Semiatin, B.W. Shanahan, F. Meisenkothen, Acta Mater. 58, 4446 (2010)

[34] C.T. Liu, P.J. Maziasz, Intermetallics 6, 653 (1998)

[35] Y.H. Wang, J.P. Lin, Y.H. He, X. Lu, Y.L. Wang, G.L. Chen, J. Alloys Compd. 461, 367 (2008)

[36] Y.Y. Chen, B.H. Li, F.T. Kong, J. Alloys Compd. 457, 265 (2008) 